\title{
Patriotas esquecidos
}

\section{Forgotten patriots}

\author{
Marco Aurélio Guimarães \\ Doutorando do Centro de Desenvolvimento Sustentável/Universidade de Brasília \\ maraugui@terra.com.br
}

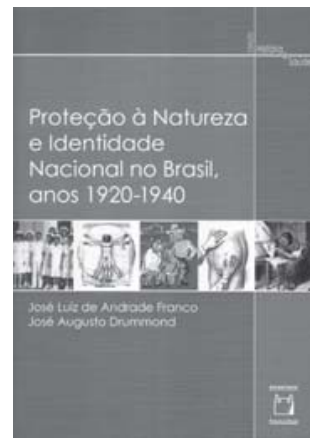

FRANCO, José Luiz de Andrade; DRUMMOND, José Augusto. Proteção à natureza e identidade nacional no Brasil, anos 1920-1940. Rio de

Janeiro: Editora Fiocruz. 2009. 272p. (Coleção História e Saúde).
Tosé osé Luiz de Andrade Franco, licenciado em história e com pósdoutorado em desenvolvimento sustentável pela Universidade de Brasília, e José Augusto Drummond, cientista social e doutor em recursos naturais e desenvolvimento pela University of Wisconsin, Madison (EUA), escreveram essa importante e emocionante revisão de obras de cientistas e funcionários públicos brasileiros engajados no estudo das relações entre a sociedade e a natureza no Brasil, nos anos 1920-1940. Os cientistas estudados são Alberto José Sampaio, Armando Magalhães Correia, Cândido de Melo Leitão e Frederico Carlos Hoehne, que influenciaram a formação e execução de políticas públicas para a proteção do patrimônio natural brasileiro e para a afirmação da identidade brasileira, durante o governo de Vargas e depois.

Para os autores, "a identidade nacional brasileira existia de forma latente, manifestada nas mais diversas formas de expressão cultural, nas maneiras de ser e nas solidariedades profundas" (p.16). É emocionante porque evoca os sentimentos mais profundos de nacionalidade, de defesa do patrimônio brasileiro e de cultura da estética. Naquela época, os conceitos de proteção, conservação e preservação eram intercambiáveis, indicando que a natureza deveria ser protegida, tanto como conjunto de recursos produtivos a serem explorados racionalmente, no interesse das gerações presentes e futuras, quanto como diversidade biológica a ser objeto de ciência e contemplação estética. O resgate da memória desses cientistas se justifica pela atualidade das discussões acerca dos problemas ambientais e da criação de cada vez mais numerosas unidades de conservação. Para isso, os autores recorrem, inicialmente, a Dean (1996) e Pádua (1997, 2002).

O período de 1920-1940 abrange a criação do Estado Novo de Vargas (1937-1945), regime em que o trabalho, a indústria e a agricultura eram motivos de debates políticos. As ferrovias paulistas, símbolo da modernização, estavam em acelerada expansão, e a agricultura de plantation do café começava a apresentar os seus riscos. Euclides da Cunha, em uma de suas viagens, sensibilizou-se com a degradação ambiental causada pela agricultura (vossorocas) e pelas ferrovias (corte raso de madeira para servir como combustível das locomotivas) (p.27).

Em 1934 aconteceu, no Rio de Janeiro, a Primeira Conferência Brasileira de Proteção à Natureza, patrocinada pelo chefe do governo provisório Getúlio Vargas e organizada pela 
Sociedade dos Amigos das Árvores, com apoio do Museu Nacional do Rio de Janeiro (MNRJ). O evento foi um marco na consciência ambientalista brasileira. Alberto José Sampaio foi seu relator. Leôncio Correia, presidente da Sociedade dos Amigos das Árvores, em seu discurso de abertura, exaltou o decreto que criou o Código Florestal, descreveu a Sociedade como a "sentinela vigilante do nosso patrimônio florestal" (p.44) e defendeu a necessidade de cooperar com as nações civilizadas do mundo, na área ambiental.

Nos EUA, desde a década de 1900-1910 conservacionistas e preservacionistas debatiam a destinação dos parques nacionais, cujo conceito se disseminou pelo mundo devido à ação do Sierra Club, fundado por John Muir. Por outro lado, os conservacionistas, cujo expoente era Ginfford Pinchot, afirmavam a possibilidade de exploração racional dos recursos naturais. O presidente Theodore Roosevelt (1901-1909), apesar de admirador da filosofia de Pinchot, ampliou o Parque Nacional de Yosemite e criou 53 reservas naturais, 16 monumentos nacionais e cinco novos parques. Os cientistas abordados no livro de Franco e Drummond conheciam esse debate, e na conferência de 1934 predominou a defesa da criação de parques destinados à contemplação estética e à pesquisa científica.

Alberto José Sampaio foi um dos mais conhecidos e respeitados botânicos do Brasil na década de 1920. Entre as várias atividades que desempenhou destaca-se a participação na expedição da comissão do marechal Cândido Rondon à serra do Tumucumaque (Amapá), para realizar estudos sobre a flora local. Durante sua carreira manteve intenso contato com a comunidade científica nacional e internacional. Foi fundador e membro da Sociedade dos Amigos das Árvores, representante do Museu Nacional do Rio de Janeiro no Conselho Florestal Federal, membro correspondente do Ofício Internacional de Proteção à Natureza e teve papel de destaque na concepção da legislação de proteção dos recursos naturais, na elaboração do Código Florestal e na efetivação do Serviço Florestal Federal.

Os autores focalizam três obras de Sampaio, O problema florestal no Brasil em 1926, Phytogeografia do Brasil e Biogeographia dynamica, que permitem compreender o seu pensamento. A primeira obra é um relatório apresentado em Roma, com o objetivo de servir "de propaganda da silvicultura e como contribuição do Museu Nacional à indústria extrativa racional" (p.68). Sampaio preocupou-se em organizar o Serviço Florestal Federal como órgão de pesquisa, controle e implementação de florestas produtivas no Brasil, além de se incumbir da criação, conservação e guarda de florestas protetoras. Em sua segunda obra, Sampaio começa a delinear o conceito de proteção à natureza, integrando o homem à natureza, porém assistido pelo poder público, de modo a garantir a esse homem formação moral e acesso a conhecimentos técnicos e científicos para produção. A proteção da natureza seria, portanto, a soma da conservação das matas com o incremento da produção. $\mathrm{Na}$ terceira obra analisada, Sampaio procurava legitimar o movimento de proteção à natureza.

O segundo autor de que trata o livro é Armando Magalhães Correia, naturalista autodidata da Seção de História Natural do MNRJ, renomado escultor e habilidoso desenhista. Seus conhecimentos e sua capacidade de produzir imagens sobre a natureza o levaram a ser professor do Museu e da Escola de Belas Artes do Rio de Janeiro. Correia destacava-se também na atividade jornalística. Em seu livro $O$ sertão carioca, chamou a atenção para a falta de assistência dos poderes públicos às pessoas do sertão e relacionou diretamente a fragilidade da proteção da natureza do sertão carioca às precárias condições de vida de seus habitantes: 
"O problema fundamental no Brasil é o de uma sadia brasilidade, a começar pelo reflorestamento, a conservação dos mananciais, para garantia de nossa fauna, e assim possa haver meios de subsistência aos seus habitantes ..." (p.89). Acreditava o cientista na possibilidade de os próprios sertanejos se transformarem nos principais protetores da natureza - desde que as autoridades lhes proporcionassem a necessária assistência e elaborassem as leis adequadas - e defendia a necessidade de regulamentação que garantisse a sobrevivência da natureza. Ademais, Correia alertou para o controle sobre a caça e o uso humano da fauna, da flora e das águas, chegando a propor a criação de parques nacionais de proteção da natureza, que permitiriam o conhecimento científico, a apreciação estética e a identidade nacional.

O terceiro autor estudado é o zoólogo Cândido de Melo Leitão. A análise de quatro de suas obras - A biologia no Brasil, A vida maravilhosa dos animais, A vida na selva e Zoogeografia do Brasil - revela sua preocupação com a natureza e seu interesse pela pesquisa científica. A primeira delas trata do surgimento e da evolução da história natural no mundo e em particular no Brasil, onde os museus tiveram papel fundamental, tais como o MNRJ, o Museu Paraense Emílio Goeldi e o Museu Paulista. O autor reconhece o avanço da botânica e da zoologia no Brasil, ressaltando que o interesse econômico pelas plantas contribuiu para o desenvolvimento da botânica. A segunda obra reúne conferências transmitidas pelo rádio sobre assuntos de zoologia e botânica, tais como as formas de organização dos seres vivos com base em seu comportamento; 'amizade e comensalidade' entre os animais; canto e dança entre os animais; consumo alimentar de insetos e aracnídeos. Nos últimos capítulos, registra o debate sobre visões de natureza. Para o autor, contrariando as ideias de Darwin, a sobrevivência dos organismos dependia da sua capacidade de cooperação. Na terceira obra, Melo Leitão ressalta a valorização as florestas tropicais, sua riqueza e diversidade e seus mecanismos complexos de interação e adaptação, o que revela seu pioneirismo na apreciação científica e estética das florestas tropicais. Para o zoólogo, os parques e as reservas naturais eram fundamentais para garantir a perpetuação da variedade de espécies da fauna e da flora. Em seu quarto livro, Melo Leitão, comprometido com um projeto de nacionalidade, com o saber científico e com a valorização da natureza, traçou um quadro geral da distribuição geográfica dos animais em terras brasileiras e da configuração de seus hábitats, além de criticar Darwin e a teoria da seleção natural.

O quarto e último autor estudado é Frederico Carlos Hoehne. Autodidata e sustentado, quando jovem, pela venda das orquídeas que produzia, Hoehne deu um salto para ingressar na carreira de pesquisador e cientista ao ser nomeado jardineiro-chefe do MNRJ, em 1907. O cargo lhe permitiu participar de duas expedições de naturalistas com Rondon a Mato Grosso e Amazonas, além de outras 15 expedições pelo Brasil e pelos países vizinhos. Hoehne coletou pelo menos dez mil espécimes de vegetais e escreveu mais de seiscentos artigos sobre plantas, arborização de estradas, desmatamento, reflorestamento, plantas exóticas, plantas medicinais, agricultura, recuperação ambiental e econômica de regiões desmatadas, criação de plantas e áreas destinadas à conservação da natureza. A convivência e o interesse pela proteção da natureza fizeram com que o cientista compartilhasse com Alberto José Sampaio ideais nacionalistas e de proteção do patrimônio natural. Sob inspiração de Hoehne foi 
fundada, em São Paulo, a Sociedade dos Amigos da Flora Brasílica, que influenciou a opinião pública quanto à necessidade de criação de reservas biológicas e de reflorestamento.

Em 1928 Hoehne viajou para Paraná e Santa Catarina a fim de estudar a imbuia (Ocotea porosa) e pesquisar sobre a fitofisionomia da região e as possibilidades de aproveitamento racional dos seus recursos naturais. Desse estudo surgiu a publicação de Araucarilândia, correspondente ao termo indígena 'curitiba', relativo à aglomeração de pinheiros, árvore típica da floresta de araucárias. Segundo o autor, a devastação era assustadora e incidia sobre um patrimônio que não poderia ser reconstruído pelo homem. Os bosques de pinheiros e imbuia estavam dando lugar a capoeiras e taperas. Hoehne propôs o plantio de bosques formados por erva-mate, imbuia e pinheiros para fins de exploração econômica. Outra característica marcante de Hoehne é a inclusão da estética nas reflexões sobre a natureza: "O senso estético não é, porém, peculiar, isto é, desenvolvido em todos os homens. Ele é natural e próprio dos seres elevados, peculiar e bem desenvolvido nos seres cultos e aprimorados, que cogitam das coisas transcendentes e sublimes ... . O estético alimenta o espírito, eleva a alma, não só de uma pessoa e em prejuízo de outras, mas de todas, em proveito da coletividade, porque o belo e o bom o são, simultaneamente, para todos, sem prejuízos de quem quer que seja" (p.180, 181).

Sampaio, Correia, Melo Leitão, Hoehne e os outros viram um Brasil infinitamente maior do que a percepção econômica dos madeireiros, no verde das suas florestas, matas e campos, nos rios e nos animais. Mas também viram um Brasil de um povo que desmata, queima e derruba florestas clandestinamente, visando somente às vantagens econômicas de cada um. Acreditavam que a natureza precisava ser conhecida e o homem, compreendido, assistido e instruído, para que pudesse valorizá-la e aproveitá-la de forma previdente. Infelizmente o foco nas atividades 'desenvolvimentistas', promovido pelos governos federal e estaduais nas décadas seguintes, levou ao esquecimento o legado desses autores, conduzindo à frustração técnicos e cientistas da época: "a natureza, fonte de vida, na verdade, contava pouco na constituição da identidade nacional” (p.219).

Com texto acessível, bem encadeado e fácil de ler, Proteção à natureza e identidade nacional no Brasil pode ser de interesse de pesquisadores, ambientalistas, estudiosos dos problemas econômicos e ambientais do Brasil, geógrafos, biólogos, historiadores e, principalmente, de brasileiros que se interessem pela história brasileira a fim de evitar os erros do passado, na exploração de nossos recursos naturais.

\section{REFERÊNCIAS}

DEAN, Warren.

A ferro e fogo: a história e a devastação da Mata Atlântica brasileira. São Paulo: Companhia das Letras. 1996.

PÁDUA, José Augusto.

A degradação do berço esplêndido: um estudo sobre a tradição original da ecologia política brasileira (1786-1888). 1997. Tese (Doutorado)
- Instituto Universitário de Pesquisas do Rio de Janeiro, Universidade do Estado do Rio de Janeiro, Rio de Janeiro. 1997.

PÁDUA, José Augusto. Um sopro de destruição: pensamento político e crítica ambiental no Brasil escravagista (1786-1888). Rio de Janeiro: Jorge Zahar. 2002. 